\title{
Removal Effect of Simulated Dairy Wastewater by SBR
}

\author{
Jinlong Zuo ${ }^{1}$, Xinguo Yang $^{1}$,Daxiang Chen ${ }^{1}$ Xiaoyue Wang ${ }^{1}$, Xuewei \\ Wang $^{1}$,Xuming Wang ${ }^{2 *}$ \\ ${ }^{1}$ Life Science and Environmental Science Research Center, Harbin Commercial University, Harbin \\ 150076,China \\ ${ }^{2}$ Beijing Agro-Biotechnology Research Center, Beijing Key Laboratory of Agricultural Genetic \\ Resources and Biotechnology, Beijing Academy of Agriculture and Forestry Sciences, \\ Beijing 100097, China
}

*Corresponding author: Xuming Wang (wangxm413@163.com),Tel. +86 13520716400

Keywords: SBR process, the dairy wastewater, removal effect

\begin{abstract}
With the development of the times, the demand for dairy becomes more and more heavily all over the world. Meanwhile, the dairy wastewater is doing more and more harm to the environment. Now the SBR(Sequencing Batch Reactor) process has been widely used in dairy wastewater treatment. The SBR process is a biologic treatment method with simple structure and nimble operation. In this paper in order to study the removal effect of dairy wastewater, the SBR process is divided into anoxic stir for 30 minutes and aeration for 3 hours. The MLSS was controlled at 2400-2600 mg/L and the sludge retention time could be controlled in 13-17 days. The results showed that the concentration of COD, ammonia nitrogen and phosphate can reach $90 \mathrm{mg} / \mathrm{L}$, $9 \mathrm{mg} / \mathrm{L}$ and $6 \mathrm{mg} / \mathrm{L}$. Therefore the SBR process can achieve the good removal effect for the dairy wastewater.
\end{abstract}

\section{Introduction}

Dairy wastewater is typical industrial waste water. With the improvement of people's economic level, the consumption of dairy products is also getting higher and higher. People are more and more demand for it. Meanwhile Water pollution comes along with it. In dairy industries, water has been a key processing medium. Water is used throughout all steps of the dairy industry including cleaning, sanitization, heating, cooling and floor washing and naturally the requirement of water is huge [1].

With the water pollution getting more and more serious, the Chinese government pays more attention to the treatment of the industrial waste water. The urban sewage treatment efficiency is constantly improving year by year. However, people still need to strengthen the awareness of environmental protection

With rapid development of soybean industry in recent years in China, the dairy wastewater is doing more and more harm to the environment. The government's demand for the construction of sewage treatment facilities is also getting higher and higher. The CASP (Conventional Activated Sludge Process) is expensive and requires a variety of space [2-3].

Irish scholar Healy et al. combined technology of artificial wetland and circulation sand filter to treat the dairy wastewater. The method avoided the direct discharge of dairy wastewater caused by surface water and groundwater eutrophication [4].

To solve such problems, the SBR process has been widely used in dairy wastewater across the world. The SBR process is a biologic treatment method with simple operation relatively low cost, which can be mixed completed and a series of biological and chemical reactions reacts in the same reactor. As a consequence, the SBR process is widely used to treat the urban domestic sewage and industrial wastewater [5-7].

The SBR process has the following advantage [8-10]:

(1) Small floor area, low cost and simple process flow; 
(2) Good running stability;

(3) Intermittent cycle operation and the high demand for automatic control;

(4) Relatively small space occupied.

In this paper in order to study the efficiency of dairy wastewater, the SBR process was investigated.

\section{Experiment}

\subsection{Experimental water quality}

Experimental wastewater was prepared by simulation. The influent wastewater characteristics were listed in Table 1.

Table 1 Influent parameters

\begin{tabular}{|c|c|c|c|}
\hline COD(mg/L) & $\mathrm{pH}$ & $\mathrm{NH}_{4}{ }^{+}-\mathrm{N}(\mathrm{mg} / \mathrm{L})$ & $\mathrm{PO}_{4}{ }^{3-}-\mathrm{P}(\mathrm{mg} / \mathrm{L})$ \\
\hline $850-1050$ & $6.7-7.3$ & $160-180$ & $30-50$ \\
\hline
\end{tabular}

\subsection{Experimental equipment}

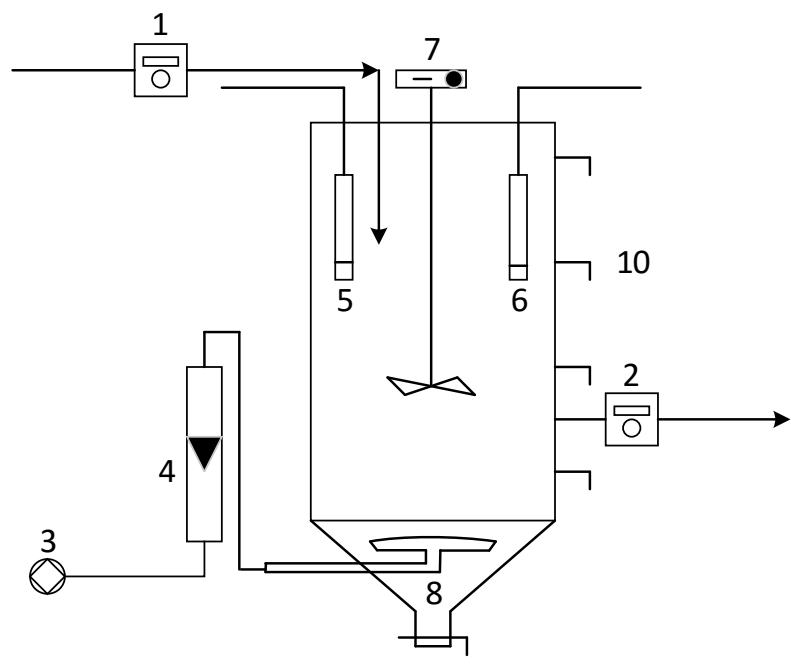

9

1. Constant flow pump 2. Cross flow pump 3. Air compressor 4. Rotor flow meter 5. DO probe 6.pH probe 7. Electric Blender 8. Disc aeration device 9. Mud outlet 10. Sampling port

Figure 1 Schematic diagram of experimental equipment

The experiment equipment was shown in the Fig.1. The reactor was made of glass. The volume of the reactor was 10L. There was a sampling device on the side of the reactor. The wastewater analytical methods were taken the standard methods

The $\mathrm{pH}$ and DO device were used to control reaction conditions. The experiment employed SBR process and instantaneous influent water, first anoxic stirring for $30 \mathrm{~min}$, then aerating for $3 \mathrm{~h}$, sedimentation for $2 \mathrm{~h}$ and drainage and lying idle. The MLSS was controlled between 2500-2600 $\mathrm{mg} / \mathrm{L}$. After a reaction cycle, 2L water was drained away.

The experiment was carried out for 60 days and the data was representative.

\subsection{Analysis factor}

Chemical oxygen demand, ammonia nitrogen and phosphate were analyzed in accordance with the standard method.

\section{Results and discussions}

(1) The removal effect of COD

During the period, the COD decreased obviously (shown in the Fig.2) When the simulated 
wastewater entered the reactor, it was diluted. After the anoxic stir for $30 \mathrm{~min}$, the COD decreased with aeration. At the end of the reaction, the COD was reduced to below $100 \mathrm{mg} / \mathrm{L}$. During the reaction stage, the removal effect of COD was obvious

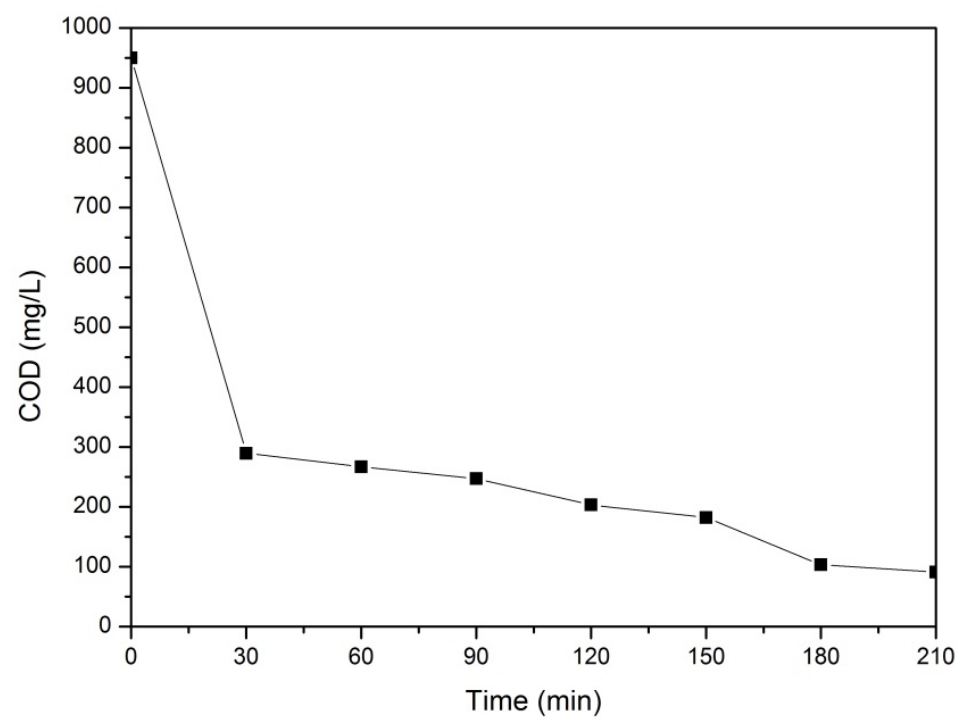

Figure 2 Change of COD concentration in a cycle

(2) The removal effect of ammonia nitrogen

During the period, the ammonia nitrogen decreased obviously (shown in the Fig.3). The concentration of ammonia nitrogen was relatively stable during period of the anoxic stir. After the aeration stage, ammonia nitrogen concentration could be lower than $10 \mathrm{mg} / \mathrm{L}$.

Due to the denitrification, the ammonia nitrogen concentration in the reaction remained little changed during the anoxic stir. Denitrifying bacteria decreased rapidly in the period. Removal of nitrogen was violent. With the aeration starting, the ammonia nitrogen concentration decreased rapidly. After 3-hour aeration, the concentration was lower than $10 \mathrm{mg} / \mathrm{L}$.

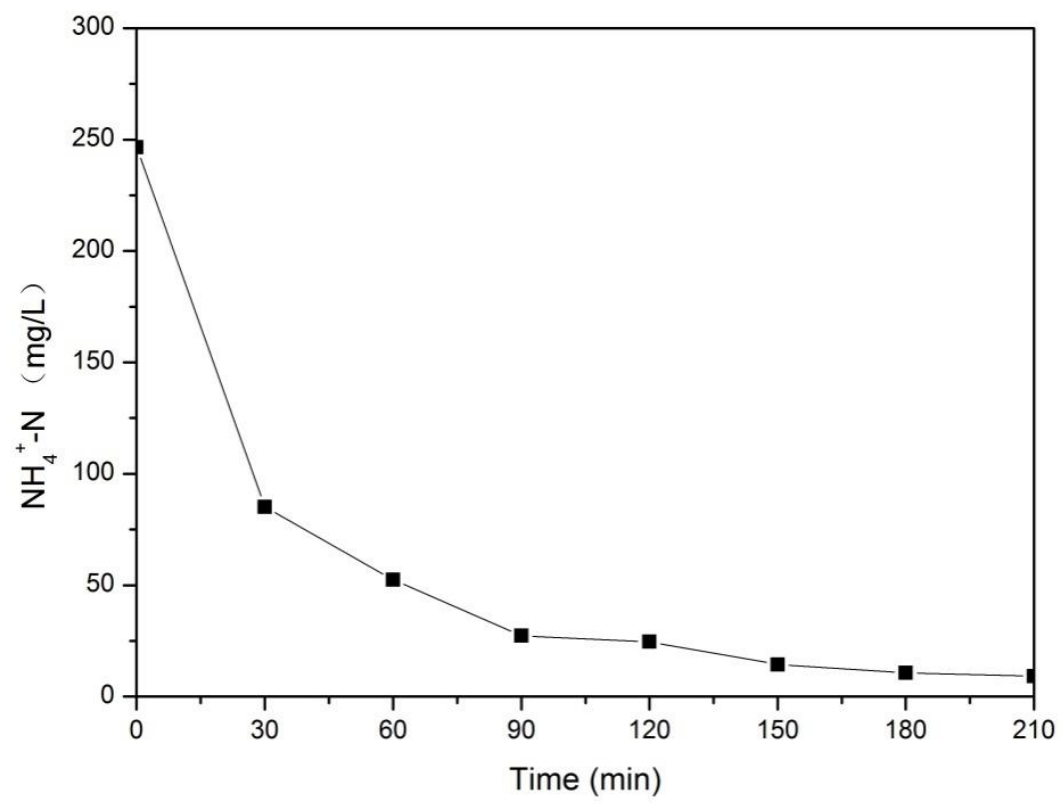

Figure 3 Change of ammonia nitrogen concentration in a cycle

(3) The removal effect of phosphate

At the primary stage of reaction, the concentration of phosphate was about $26.8 \mathrm{mg} / \mathrm{L}$. At the end 
of the anoxic stir, the concentration reached the maximum (shown in Fig.4). The reason was that phosphate accumulated in granular sludge released under anoxic condition. At the aeration stage, phosphorus accumulating bacteria absorbed the phosphorus excessively under aerobic conditions. At the end of the reaction, phosphate concentration could be under $3 \mathrm{mg} / \mathrm{L}$ which was allowed to be discharged.

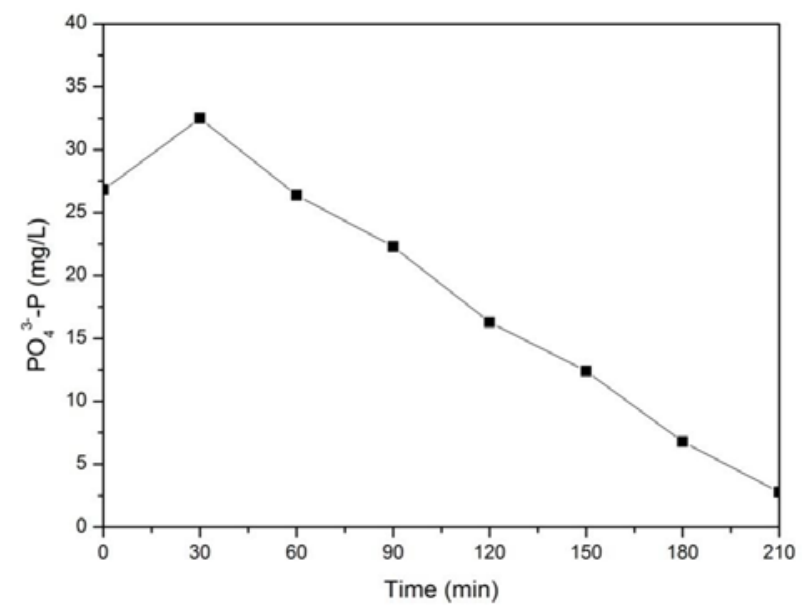

Figure 4 Change of phosphate concentration in a cycle

\section{Conclusion}

(1) During the reaction, the removal effects of COD were significant. After the aeration, the concentration of COD decreased. At the end of the reaction, the concentration of COD could be lower than $100 \mathrm{mg} / \mathrm{L}$.

(2) The concentration of ammonia nitrogen kept stable at the period of anoxic stir. When the aeration began, the concentration of ammonia nitrogen decreased rapidly. When the reaction stopped, it could be lower than $6 \mathrm{mg} / \mathrm{L}$.

(3) The concentration of phosphorus increased slowly until the anoxic stir stopped. The peak was $32.5 \mathrm{mg} / \mathrm{L}$. When aeration began, the concentration was steadily dropping in the system until the aeration stopped.

According to the experiment data, the main analysis project of effluent was good after 3-hour aeration. The simulated dairy wastewater could be treated up to the standard by the SBR process.

\section{References}

[1] Sarkar B, Chakrabarti P P, Vijaykumar A, et al. Wastewater treatment in dairy industries possibility of reuse[J]. Desalination, 2006, 195(1-3):141-152.

[2] Rodrigues A C, Melo L F. Posttreatment of a brewery wastewater using a sequencing batch reactor.[J]. Water Environment Research A Research Publication of the Water Environment Federation, 2001, 73(1):45-51.

[3] Pierson J A, Pavlostathis S G. Real-Time Monitoring and Control of Sequencing Batch Reactors for Secondary Treatment of a Poultry Processing Wastewater[J]. Water Environment Research, 2000, 72(5):585-592.

[4] Healy M G, Rodgers M, Mulqueen J. Treatment of dairy wastewater using constructed wetlands and intermittent sand filters.[J]. Bioresource Technology, 2007, 98(98):2268-81.

[5] Neczaj E, Kacprzak M, Lach J, et al. Effect of sonication on combined treatment of landfill leachate and domestic sewage in SBR reactor[J]. Desalination, 2007, 204(1):227-233.

[6] Su W J, Luo J Z. Investigation of Treatment of Domestic Sewage by PAC-SBR Process[C]// 
Bioinformatics and Biomedical Engineering, (iCBBE) 2011 5th International Conference on. 2011:1-4.

[7] Li M, Song X. Treatment of domestic sewage by anaerobic/aerobic/anoxic SBR process [J]. Industrial Water Treatment, 2013.

[8] N. Puznava, M. Payraudeau, D. Thornberg. Simultaneous nitrification and denitrification in biofilters with realtime aeration control[J]. Water Science and Technology, 2000, 43(1): 269-276

[9] Liu X H. Discussion on the Advantages of SBR Process in the Treatment of Mine Domestic Wastewater[J]. Sci-Tech Information Development \& Economy, 2011.

[10] S. Park, B. J. Kim, S. Y. Jung. Simulation Methods of a System Dynamics Model for Efficient Operations and Planning of Capacity Expansion of Activated-sludge Wastewater Treatment Plants[J]. Procedia Engineering, 2014(70): 1289-1295 